\title{
Circadian Rhythmicity Restored by Neural Transplant. Immunocytochemical Characterization of the Graft and Its Integration with the Host Brain
}

\author{
Michael N. Lehman, ${ }^{1, a}$ Rae Silver, ${ }^{2}$ W. R. Gladstone, ${ }^{2}$ Robert M. Kahn, ${ }^{2}$ Marie Gibson, ${ }^{3}$ and Eric L. Bittman ${ }^{4}$ \\ 'Department of Anatomy and Cell Biology, Columbia University College of Physicians and Surgeons, New York, New York \\ 10032; '2Department of Psychology, Barnard College of Columbia University, New York, New York 10027; ${ }^{3}$ Department of \\ Medicine, Mount Sinai School of Medicine, New York, New York 10128; and ${ }^{4}$ Department of Zoology, University of \\ Massachusetts at Amherst, Amherst, Massachusetts 01003
}

\begin{abstract}
It is well established that overt circadian rhythms are permanently disrupted following lesions of the hamster hypothalamic suprachiasmatic nucleus (SCN). In the present study, we show that implantations of brain grafts containing the fetal SCN reestablish circadian rhythms of locomotor activity in adult hamsters previously made arrhythmic by SCN lesions. The restoration of free-running rhythms in conditions of constant darkness is correlated with the presence in the graft of neuropeptides normally present in the SCN of unlesioned hamsters, including vasoactive intestinal polypeptide (VIP), neuropeptide Y (NPY), and vasopressin (VP). In several recipients, grafts were found to receive retinal input, and appeared to send efferents into the host brain. Not all functions of the SCN were reinstated by the graft: animals with restored locomotor rhythms did not show gonadal regression in the absence of light, and failed to synchronize (entrain) to light intensities to which $\mathrm{SCN}$-intact animals responded.
\end{abstract}

In the natural environment, animals restrict many behavioral and physiological events to particular times of day. Under constant conditions, such oscillations often persist (free-run) within a period that differs slightly but reliably from $24 \mathrm{hr}$. For example, the period for rhythms of locomotor activity of golden hamsters exposed to continuous darkness is approximately $24.1 \mathrm{hr}$ (Pittendrigh and Daan, 1976); the nocturnal pattern observed in a light: dark cycle reflects synchronization (entrainment) of an endogenous clock to a periodic environment.

The suprachiasmatic nuclei (SCN) of the hypothalamus are required for expression of multiple endogenous daily (circadian) rhythms. Destruction of the SCN eliminates these rhythms (Moore and Eichler, 1972; Stephan and Zucker, 1972; Rusak and Zucker 1979). These nuclei exhibit unique electrophysio-

\footnotetext{
Received Apr. 10, 1986; revised Nov. 28, 1986; accepted Dec. 15, 1986.

This work was supported by NIH Grant HD 20463 to M.N.L., NIMH Grant 29380 and a grant from the Whitehall Foundation to R.S., Grant NS 20335 to M.G., and NIH Grant HD 20018 to E.L.B. E.L.B. is a Sloan Foundation Fellow in Neuroscience. We thank Robyn Crandell for surgical help, Helen I Iirschbein for histological assistance, and Dr. A. Fleming for comments on the manuscript.

Correspondence should be addressed to Dr. Michael N. Lehman, Department of Anatomy and Cell Biology, University of Cincinnati College of Medicine, 231 Bethesda Avenue, Cincinnati, OH 45267-0521.

Present address: Department of Anatomy and Cell Biology, University of Cincinnati College of Medicine, 231 Bethesda Avenue, Cincinnati, OH 452670521 .
}

Copyright (c) 1987 Society for Neuroscience $0270-6474 / 87 / 061626-13 \$ 02.00 / 0$ logical (Inouye and Kawamura, 1979) and metabolic (Schwartz and Gainer, 1977; Reppert and Schwartz, 1983) rhythms, further supporting the suggestion that they function as a circadian clock. Destruction of the SCN also disrupts the hamster's circadian-based photoperiodic response: whereas these seasonal breeders normally regress their gonads in short photoperiods or in constant darkness, SCN-lesioned animals maintain testicular activity regardless of day length (Rusak and Morin, 1976; Stetson and Watson-Whitmyre, 1976; Elliott, 1981). Transplantation of fetal nervous tissue has proven to be a valuable tool for examining the function of specific areas of the brain (Arendash and Gorski, 1982; Krieger et al., 1982; Bjorklund and Stenevi, 1984; Gash and Sladek, 1984). Although restoration of rhythmicity with transplants in SCN-lesioned animals has been reported (Drucker-Colin et al., 1984; Sawaki et al., 1984), these studies have neither documented integration of the transplant with the host brain nor correlated peptide expression within the graft with the recovery of free-running rhythms. We have used immunocytochemical and tract-tracing techniques to characterize SCN grafts and their connections, and to examine their participation in the restoration of circadian function. The results indicate that fetal SCN grafts that restore locomotor rhythmicity in SCN-lesioned hamsters contain neuropeptidergic cells characteristic of the intact $\mathrm{SCN}$, receive retinal afferents, and appear to establish efferent connections with the host brain.

\section{Materials and Methods}

Adult male golden hamsters (LVG: LAK strain) received bilateral SCN lesions under pentobarbital anesthesia using a Grass LM-5 DC lesion maker. Stainless steel insect-pin electrodes, insulated with epoxylite except at the tips $(0.25 \mathrm{~mm})$, were stereotaxically lowered to $0.5 \mathrm{~mm}$ anterior to bregma, $0.1 \mathrm{~mm}$ lateral to the midline, and $8.0 \mathrm{~mm}$ below dura, and a $0.55 \mathrm{~mA}$ current was administered for $15 \mathrm{sec}$. Following surgery, animals were allowed ad libitum access to running wheels. A dim red safe light, which gencrated less than 1 lux (Kodak filter No. 2, $7.5 \mathrm{~W}$ bulb), allowed for animal maintenance, and a $91 \mathrm{~dB}$ white noise generator masked environmental sounds. Locomotor activity was continuously monitored by computer (Kahn et al., 1984) during either of 2 protocols: 1 week of light : dark (LD) 12:12 hr (daytime light intensity, 210 lux), followed by 4 weeks of constant darkness (DD); or 3 weeks of $L D$ 12:12 followed by 2 weeks of DD. Visual inspection of the running records verified the lack of overt circadian rhythmicity or entrainment in experimental animals.

Hamsters were anesthetized with pentobarbital and placed in a stereotaxic device for implantation in the third ventricle of fetal tissue containing the SCN (Gibson et al., 1984). Grafts were stereotaxically lowered $7.6 \mathrm{~mm}$ below bregma into the third ventricle, using the opening in the skull through which the SCN lesion had been made. Implants 


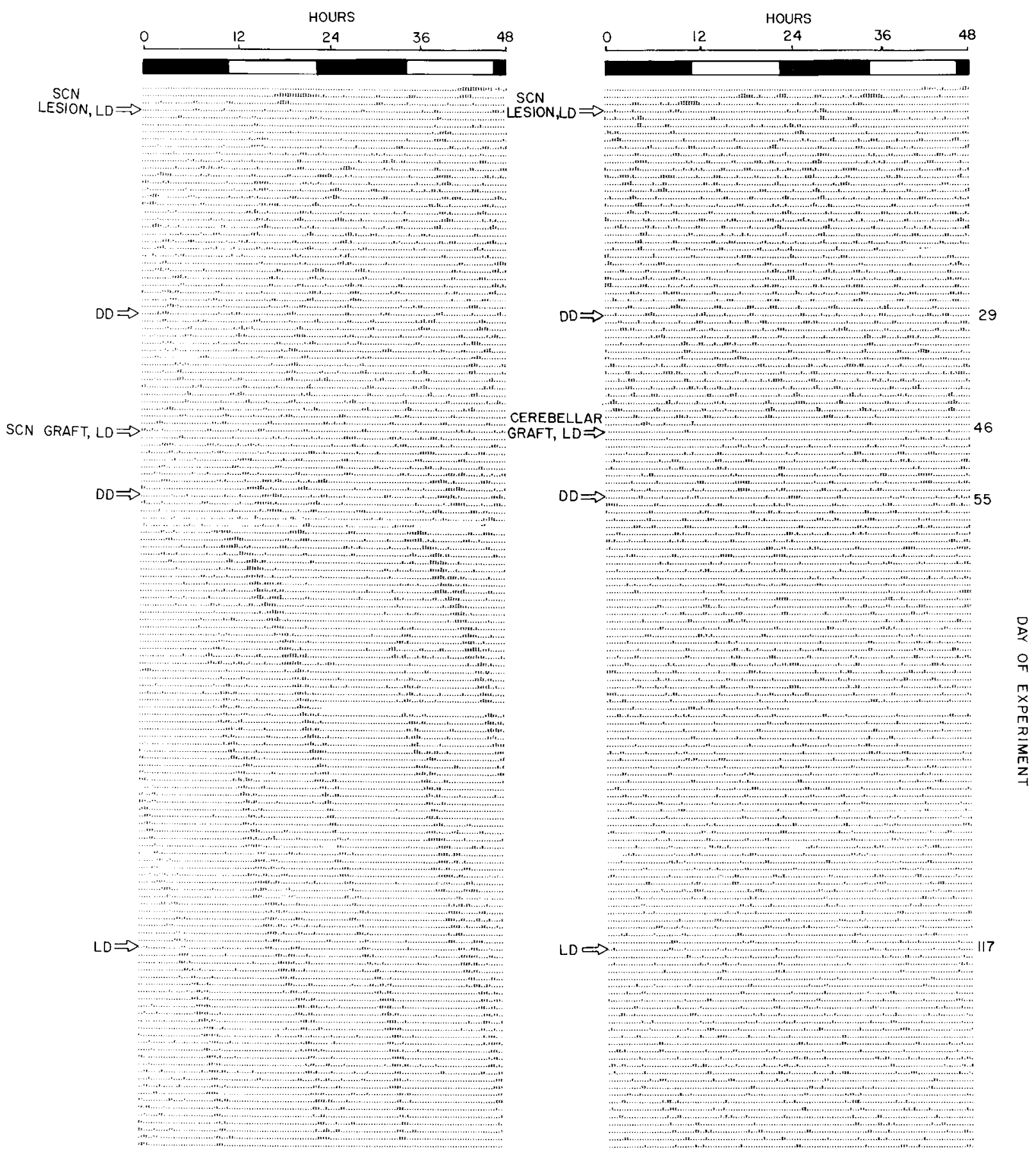

Figure 1. Double-plotted locomotor activity records of 2 male SCN-lesioned golden hamsters showing no entrainment in LD and arrhythmic running activity in DD. Forty-six days after the start of the record, hamsters were placed in LD for $9 \mathrm{~d}$ and received a graft containing either fetal $\mathrm{SCN}$ tissue (left panel) or cerebellar tissue (right panel). As can be seen from the record, a free-running rhythm of locomotor activity emerged after $6 \mathrm{~d}$ in DD in the hamster bearing the $S C N$ graft, while the animal given a cerebellar implant continued to be arrhythmic. A split in the pattern of locomotor activity appeared after 2 weeks in the hamster with an SCN implant.

$\left(0.5 \mathrm{mmml}^{3}\right)$ were obtained from the brains of hamster embryos at day 15 of gestation (day 1 being the first day after mating). Pregnant female hamsters were killed with an overdose of sodium pentobarbital; pups were quickly removed and their brains dissected out and placed upon a sterile petri dish on ice. Using aseptic techniques, fetal tissue was microdissected from the ventral surface of the hypothalamus with coronal cuts just rostral and caudal to the optic chiasm and with lateral cuts equidistant from the midline. Embryonic segments from 2 donors were pooled in sterile saline and injected into each animal via a modified 20 -gauge needle. The time between microdissection and implantation of the fetal tissue did not exceed $2 \mathrm{hr}$. Control animals were implanted with a comparable amount of cerebellar tissue. Hamsters were then returned to running wheels and maintained in LD 12:12 for 1-3 weeks, after which constant darkness was resumed. Since the circadian system mediates testicular regression in hamsters maintained in photoperiods of less than $12.5 \mathrm{hr}$ (Gaston and Menaker, 1967), we measured transscrotal testicular width at the time of the transplant and after 11 weeks of DD (Elliott, 1976; Turek and Losee, 1979). Finally, hamsters were again tested for entrainment for an additional 2-8 weeks in LD 12:12.

At the end of this sequence of behavioral tests, hamsters were anesthetized and $10 \mu$ of $1 \%$ wheat germ agglutinin (WGA) in PBS, pH 7.3, was injected into each eye for subsequent visualization of possible retinal 

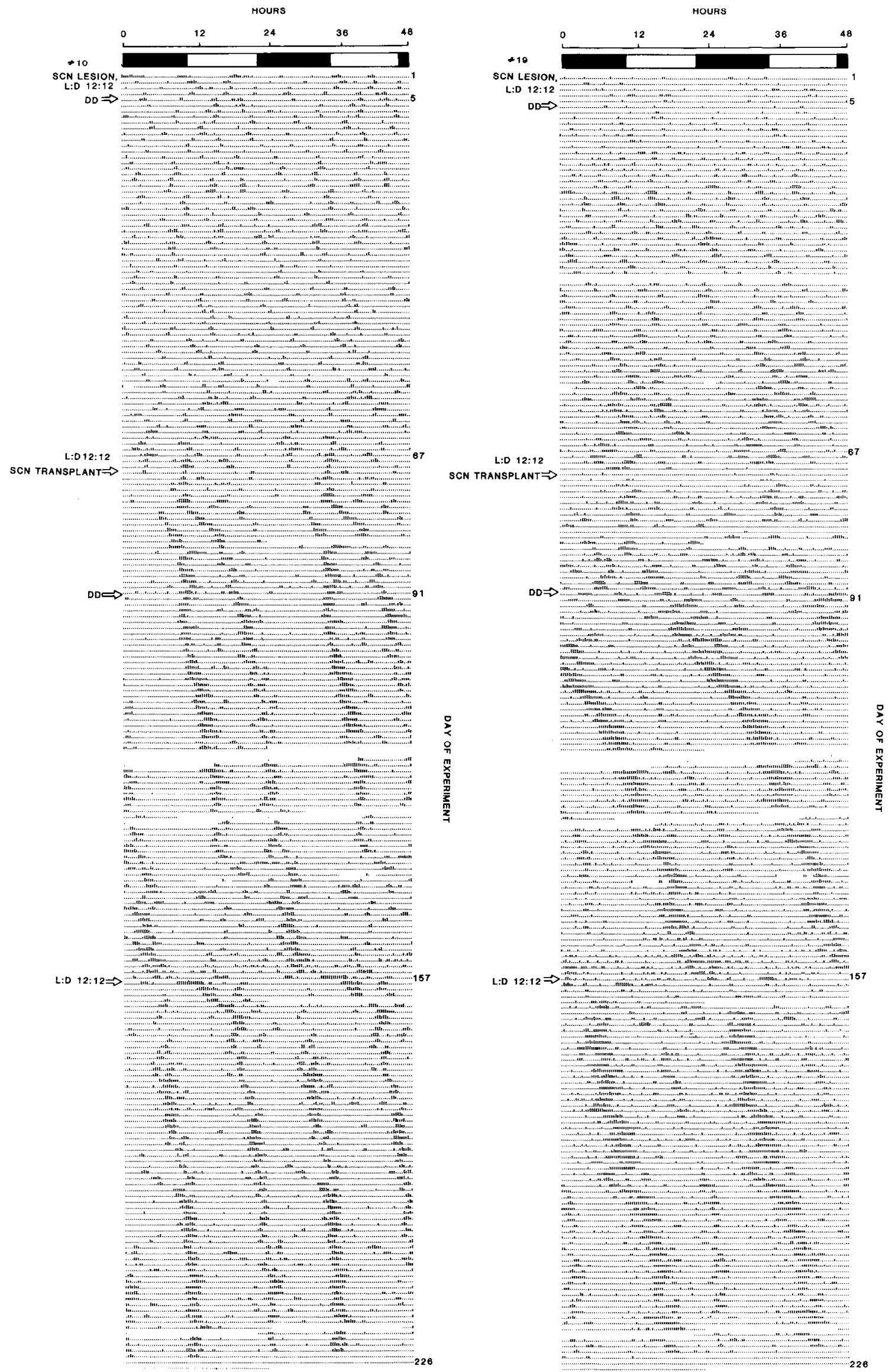

Figure 2. Double-plotted locomotor activity records of 2 male SCN-lesioned hamsters in which fetal SCN grafts restored free-running rhythms. Both animals showed a split in their pattern of locomotor activity. 


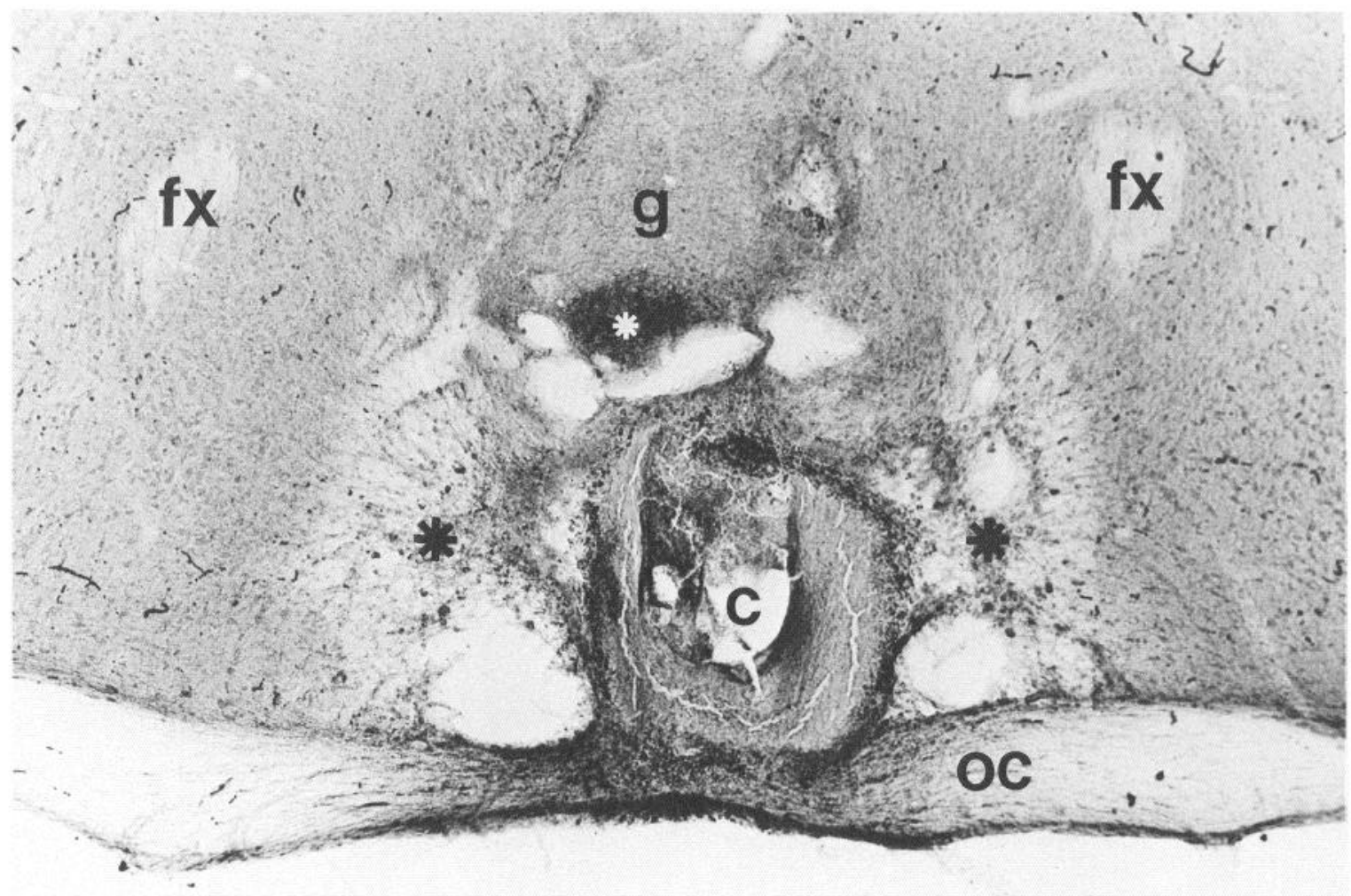

Figure 3. Low-power photomicrograph of a coronal brain section showing the size and location of an SCN lesion in a grafted hamster. The iron deposit core $(c)$ resulting from the electrolytic lesion is surrounded by necrotic and gliotic tissue (black asterisks). This section was immunostained for VIP and a small portion of the graft $(g)$ containing a cluster of VIP cells (white asterisk) can be seen above the lesion. $f x$, Fornix; oc, optic chiasm.

afferents to the graft (Ruda and Coulter, 1982). At the same time, a $2.5 \%$ solution of phaseolus vulgaris leucoagglutinin (PHA-L) in the same vehicle was iontophoretically applied (by means of a glass micropipette with a tip diameter of $20 \mu \mathrm{m} ; 5 \mu \mathrm{A}$ DC current for $15 \mathrm{~min}$ ) into the graft in order to visualize possible efferent fibers (Gerfen and Sawchenko, 1984). After survival for $2 \mathrm{~d}$, hamsters were perfused with $4 \%$ paraformaldehyde in $0.1 \mathrm{M}$ phosphate buffer, $\mathrm{pH} 7.3$, and $50 \mu \mathrm{m}$ sections were cut on a Vibratome. Serial sections through the graft were stained immunocytochemically for the presence of the following peptides, characteristic of the normal SCN (Card and Moore, 1984): vasoactive intestinal polypeptide (VIP), neuropeptide Y (NPY), somatostatin (SOM), and either neurophysin (NP) or vasopressin (VP). In several animals, sections adjacent to those stained for VIP were incubated with antiserum against peptide histidine isoleucine ( $\mathrm{PHI})$.

Prior to incubation in primary antisera, sections were washed overnight in phosphate buffer, $\mathrm{pH} 7.3$, to remove excess aldehydes, and for $10 \mathrm{~min}$ in $0.3 \%$ hydrogen peroxide to reduce endogenous peroxidase activity. Sections were incubated for $48 \mathrm{hr}$ at $4^{\circ} \mathrm{C}$ in primary antisera to either VIP, SOM, or VP (ImmunoNuclear Corp.), NPY or PHI (Cambridge Research Biochemicals), NP (kindly provided by Dr. Gaj Nilaver), or WGA or PHA-L (Vector Laboratories). After incubation in the primary antiserum, sections were incubated with biotinylated second antibodies, followed by an avidin-biotin-HRP conjugate (Vectastain, Vector Laboratories), according to the instructions of the supplier. Diaminobenzidine was the chromagen for the HRP reaction product, with glucose and glucose oxidase used to generate the hydrogen peroxide substrate (Itoh et al., 1979). Control sections in which the primary antiserum was omitted or absorbed with synthetic peptide or lectin (Peninsula Laboratories) completely eliminated reaction product. Alternate sections were counterstained with thionin; all sections were examined under bright-field and dark-field microscopy.

\section{Results}

Transplants of fetal SCN restored free-running locomotor rhythms in 10 of 14 hamsters (Fig. 1, left panel; Fig. 2), while transplants of cerebellar tissue were ineffective in restoring such rhythms (Fig. 1, right panel). The period of these rhythms in successful implants was $24.16 \pm 0.03 \mathrm{hr}$ (mean \pm SEM). In 9 of 10 subjects with restored rhythmicity, locomotor patterns split (Pittendrigh and Daan, 1976; Turek et al., 1982) into 2 components which free-ran with different periods before establishing a stable $12 \mathrm{hr}$ phase relation. Upon return to $12 \mathrm{~L}: 12 \mathrm{D}$, unequivocal entrainment did not occur. Measurement of testis width and weight (after 11 weeks of DD and when killed, respectively) consistently revealed large gonads [testis width ( $\mathrm{mm})$, $11.14 \pm 0.94$, mean \pm SEM; combined testis weight $(\mathrm{gm}), 2.99 \pm$ 0.11 , mean \pm SEM] , demonstrating the lack of an appropriate reproductive response to the photoperiod despite the resumption of free-running locomotor rhythms. Three SCN-lesioned control animals that received implants of cerebellar cortex showed no return of circadian rhythmicity (Fig. 1, right panel), failed to respond to L:D cycles, and maintained large gonads throughout the experiment.

Histological examination confirmed the presence of large, bilaterally complete lesions of the SCN in all grafted animals (Fig. 3). Furthermore, immunocytochemical and tract-tracing analyses of peptide cells and retinal afferents in the rostral hypothalamus (see below) confirmed the absence of the host SCN. Large, well-vascularized grafts were situated within the third ventricle, either in the rostral hypothalamus above the optic chiasm (Fig. $4 A$ ) or in the middle hypothalamus at the level of the paraventricular nuclei (Fig. 4C). In addition, 2 grafts that restored rhythmicity were found outside the third ventricle, one in the foramen of Monro and the other in the lateral ventricle (Fig. $4 B$ ). The border of the graft with the host brain was often 

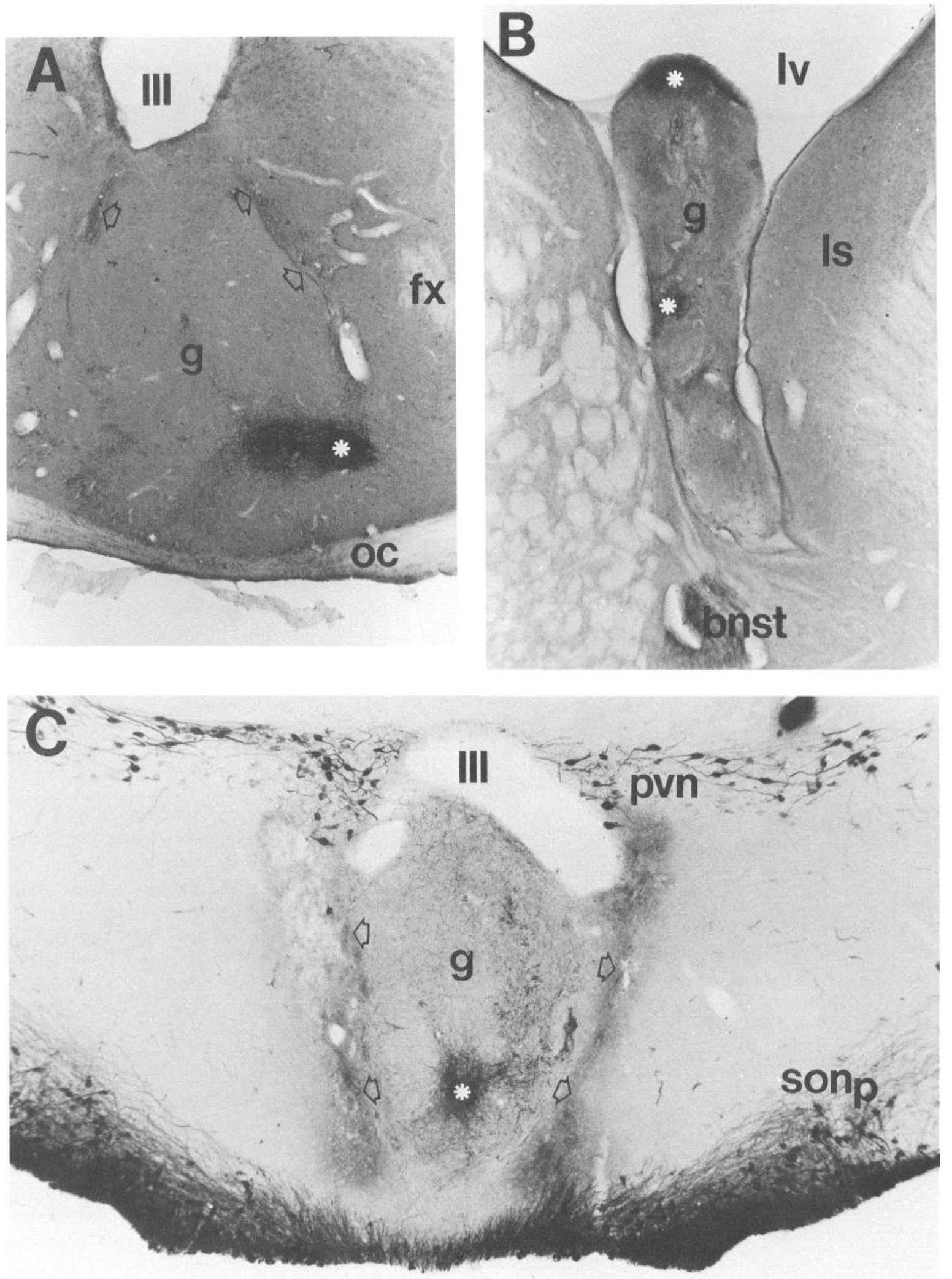

Figure 4. Low-power photomicrographs showing the location of fetal SCN grafts that restored locomotor rhythmicity, and neuropeptide cell clusters within those grafts. In this figure and in Figures 5 and 6 , individual immunoreactive neurons are difficult to discern because of the thickness of the tissue and low magnification. A. Fetal graft $(g)$ situated in the rostral third ventricle $(I I I)$ that contains a cluster of immunostained VIP cells and fibers (white asterisk). The graft entirely occupies the lesioned area above the optic chiasm (OC), where the host SCN was originally located. The ependymal cell layer of the third ventricle (arrows) sometimes formed a border between the graft and host brain but was often absent. $f x$, Fornix. $B$, Graft $(g)$ situated within the lateral ventricle $(l v)$ that contains 2 VIP cell clusters (asterisks). Note VIP fiber plexus within the bed nucleus 

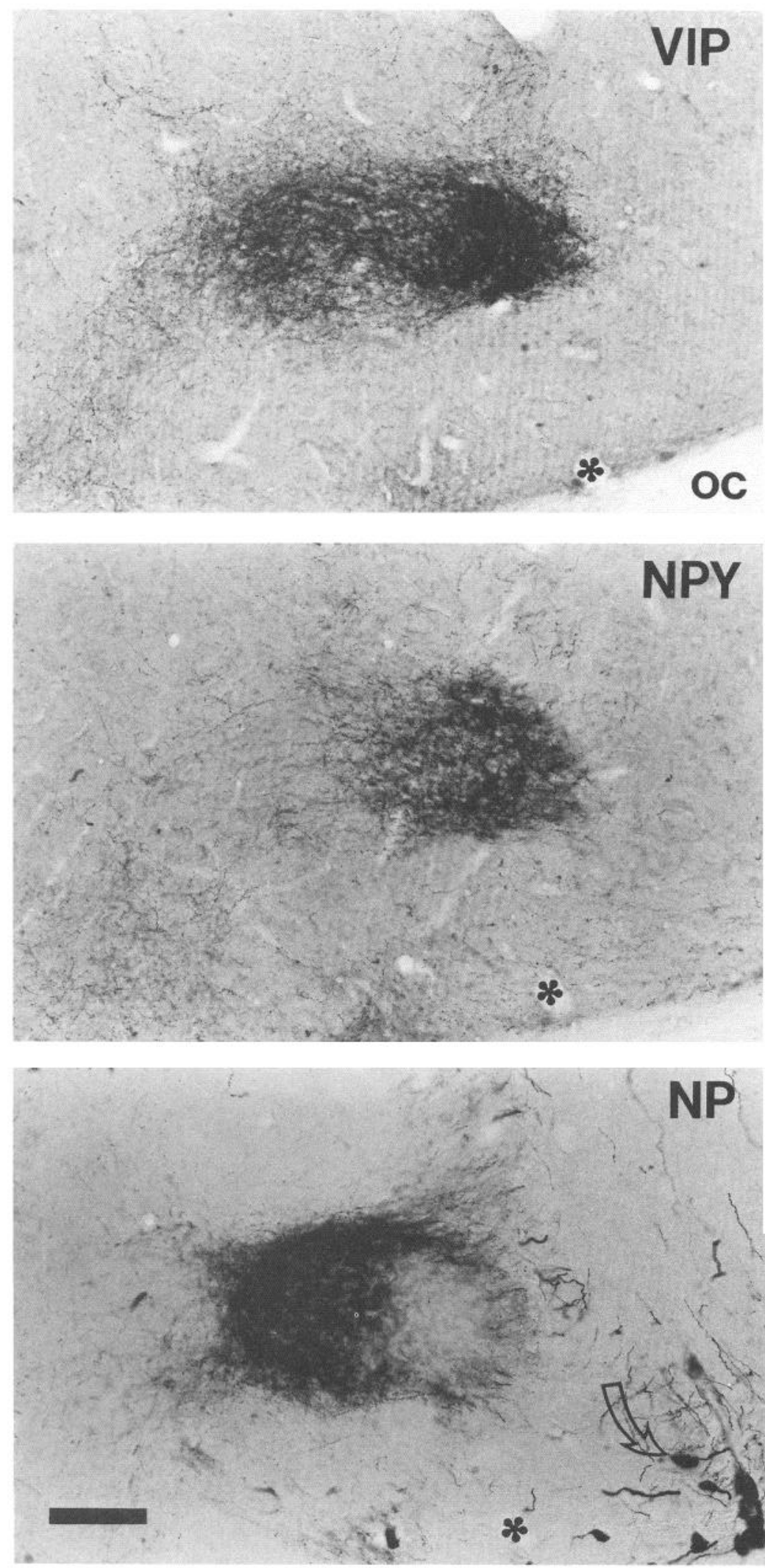

Figure 5. Serial sections showing the parcellation (top to bottom) of VIP cells and fibers, $N P Y$ fibers, and $N P$ cells and fibers within the graft shown in Figure 4A. Asterisk marks a blood vessel for orientation. Arrow in bottom photomicrograph indicates magnocellular NP cell in the host supraoptic nucleus. $o c$, Optic chiasm. Bar, $100 \mu \mathrm{m}$.

of the stria terminalis (bnst) of the host brain. $l s$, Lateral septum. $C$, Fetal graft $(g)$ located in the third ventricle $(I I I)$ at the level of the paraventricular nucleus (pvn). A cluster of parvicellular vasopressin (VP) cells and fibers can be seen within this graft (asterisk), as well as magnocellular VP cells in the host PVN and posterior supraoptic nuclei $\left(s n_{p}\right)$ and their projections in the neurohypophyseal tract (ventral surface). Graft is bordered by gliotic tissue (arrows), perhaps a remnant of the SCN lesions, except at its ventral edge, where graft tissue merges with the host brain. 

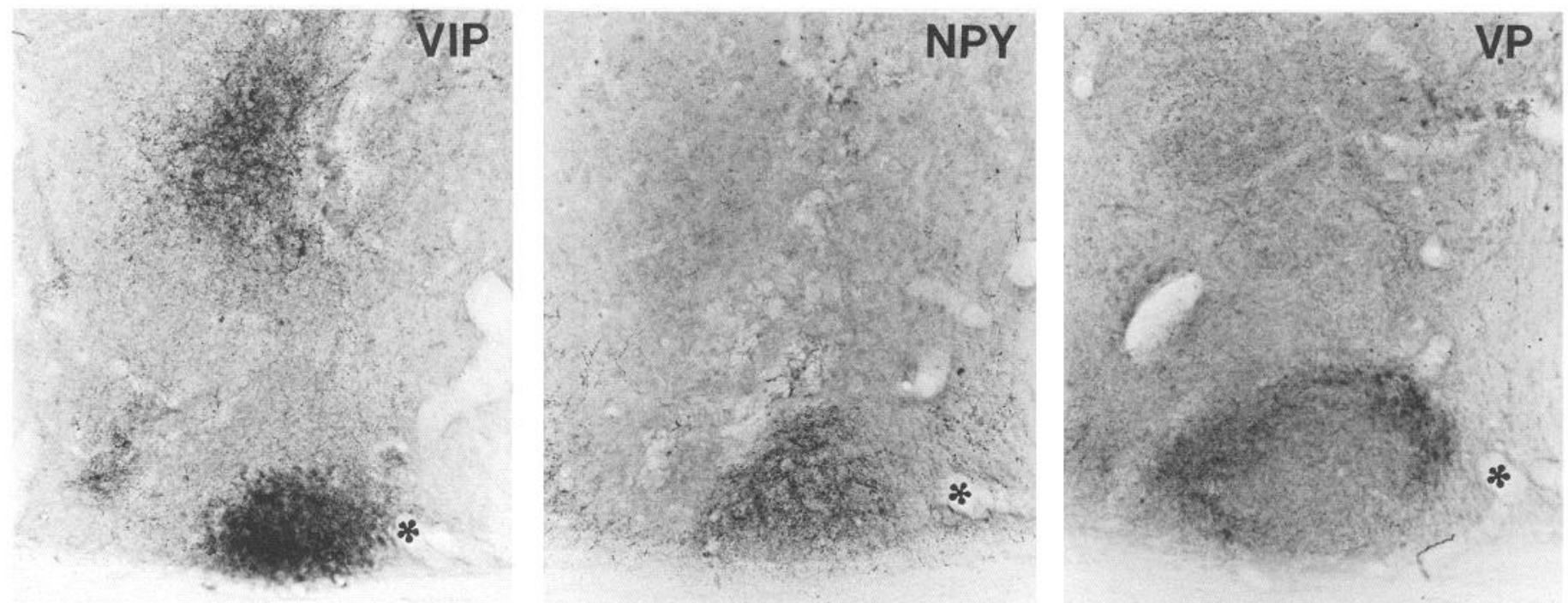

ac

Figure 6. Serial sections showing the location (left to right) of VIP cells and fibers, NPY fibers, and VP cells and fibers within a graft located above the anterior commissure $(a c)$ in the rostral third ventricle and foramen of Monro. Asterisks marks a common blood vessel for orientation. Bar, $100 \mu \mathrm{m}$.

difficult to determine, varying from well-defined remnants of the ependymal cell layer of the third ventricle to areas where the grafted tissue appeared to merge with that of the host brain. The graft located in the lateral ventricle appeared (Fig. $4 B$ ) to be entirely surrounded by ventricular space; direct contact with the host brain was not observed.

Grafts that restored locomotor rhythms also contained neuropeptides characteristic of the SCN in normal hamsters (Card

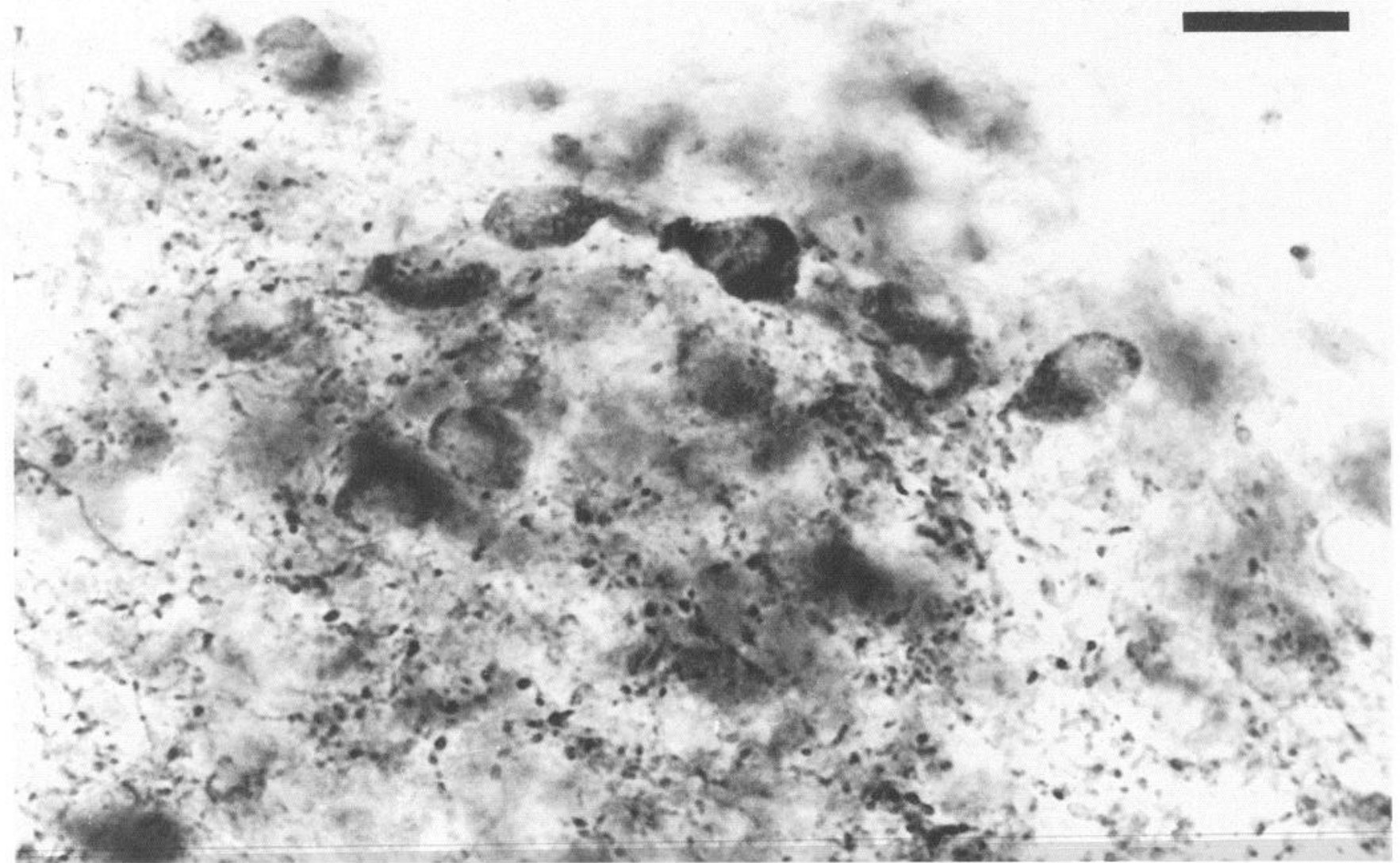

Figure 7. High-power photomicrograph of immunopositive VIP cells and fibers in a cluster within a fetal SCN graft. Bar, $10 \mu \mathrm{m}$. 


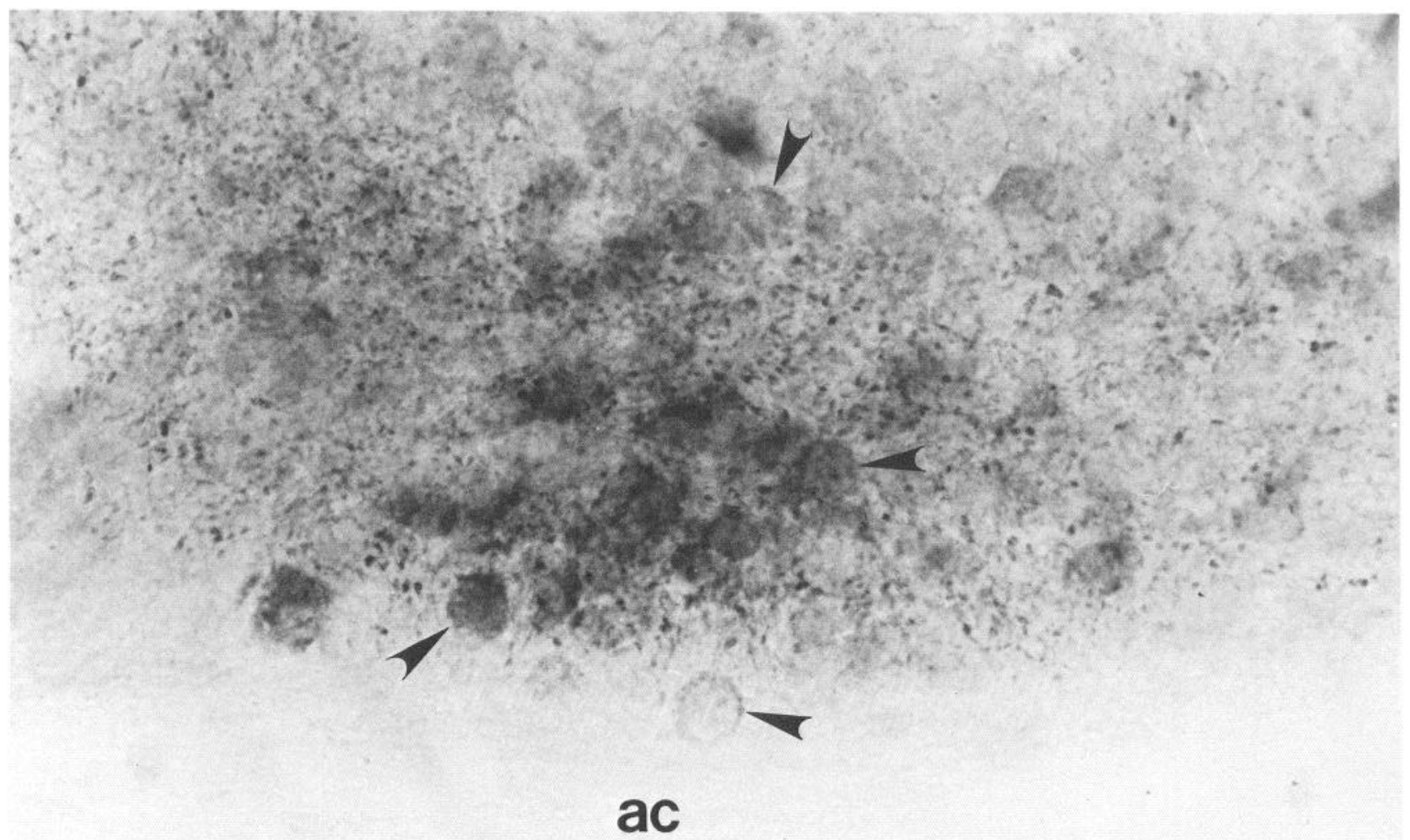

Figure 8. Photomicrograph of clustered neurons (arrows) and fibers immunostained for PHI, and located above the anterior commissure (ac) in the same graft shown in Figure 5. This section is immediately rostral to that of the left panel of Figure 6 . Bar, $20 \mu \mathrm{m}$.

and Moore, 1984). Each functional graft contained groups of VIP-immunoreactive cells giving rise to fibers that formed a plexus adjacent to the cell cluster and ramified throughout portions of the graft (Figs. $4, A, B ; 5 ; 6$ ). These VIP cells, like those of the intact SCN (Card and Moore, 1984), possessed a spherical or slightly elongated soma, approximately $8-10 \mu \mathrm{m}$ in diameter (Fig. 7). Adjacent sections to those containing VIP cell clusters revealed PHI-positive neurons in the same location (Fig. 8). At least some VIP fibers appeared to leave the graft and innervate the adjacent medial hypothalamus, especially at sites where the ependymal cell layer of the third ventricle bordering the graft was absent and graft tissue merged with that of the host. Immu: oreactive NPY fibers entered the graft from the host brain and ramified in a plexus that overlapped the location of the VIP cell cluster (Figs. 5, 6). Parvicellular NP- or VP-positive perikarya were clustered adjacent to VIP cells (Figs. 5, 6), and their fibers also ramified within the graft. Results obtained from the use of either NP or VP antisera in adjacent sections consistently revealed the same pattern of staining in the graft as well as the host brain. Occasional magnocellular VP neurons were found in the graft but not in association with the SCN-like cell clusters. Functional grafts did not contain SOM-immunoreactive cells, although scattered SOM fibers were occasionally found at a distance from VIP or VP cell groups, and SOM-positive perikarya were always seen in the host cerebral cortex.

In the 4 animals that failed to resume free-running rhythms despite SCN implants, the pattern of peptide immunostaining within the graft described above was either lacking or incom- plete. One of the experimental animals that failed to resume locomotor rhythmicity had no histologically discernible graft. Two other such animals possessed healthy, well-vascularized grafts, but lacked any apparent staining within the graft for the neuropeptides described above. The remaining subject had a graft that contained a small cluster of VIP cells and overlapping NPY fibers, but lacked an associated cluster of NP cells or fibers. In the same sections, NP immunoreactivity was evident in the host paraventricular and supraoptic nuclei. Control animals with cerebellar implants possessed large, viable, and well-vascularized grafts lacking in immunocytochemical staining for the peptides under study.

Iontophoretic applications of PHA-L directed toward the graft varied in their actual location, and resulted in heavy labeling of neurons and processes within the graft (Fig. 9A) in only 2 animals with successful implants. In these subjects, immunoreactive PHA-L fibers could be traced from labeled cells to the border of the graft. Most labeled fibers appeared to terminate at the ependymal cell layer border of the graft (Fig. 9B). However, a number of labeled fibers did appear to enter the adjacent host hypothalamus (Fig. 9C), especially where the border of the graft was indistinct and graft tissue merged with that of the host brain.

Retinal innervation of SCN grafts was evident in 4 recipients (Fig. 10A). The lectin WGA labeled small, punctate varicosities apparently within and between neurons of the graft (Fig. 10B). Analysis of adjacent sections from these animals revealed that WGA-labeled varicosities were in close proximity to VIP cell 


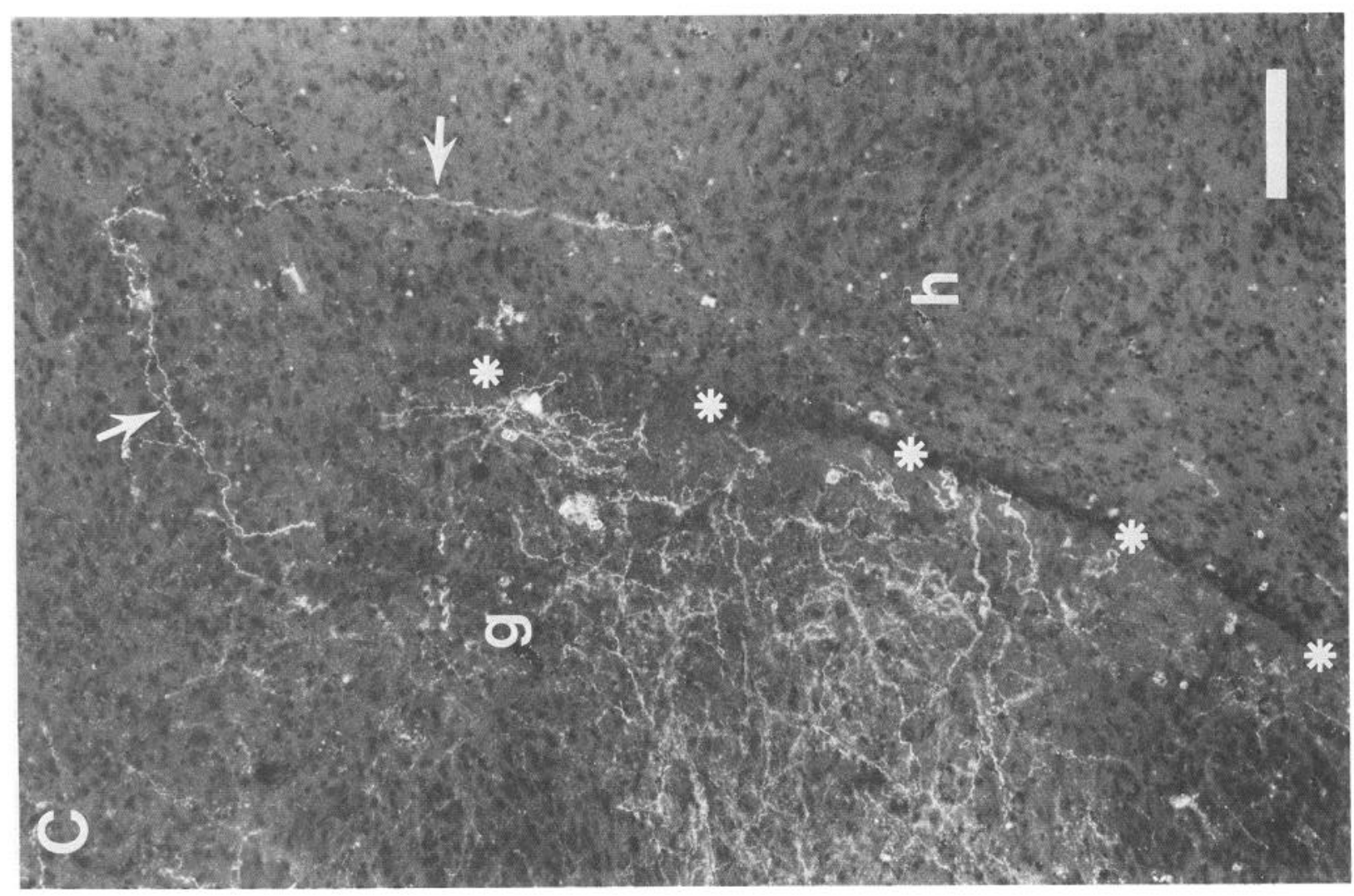

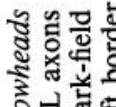

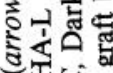

政U

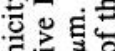

E己

.

国

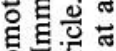

80

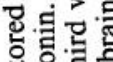

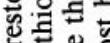

4 平

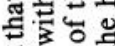

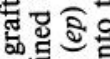

त्ञ

क्ष

용

릉요

ํㅛ

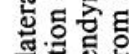

论

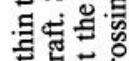

苟和

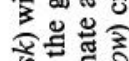

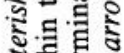
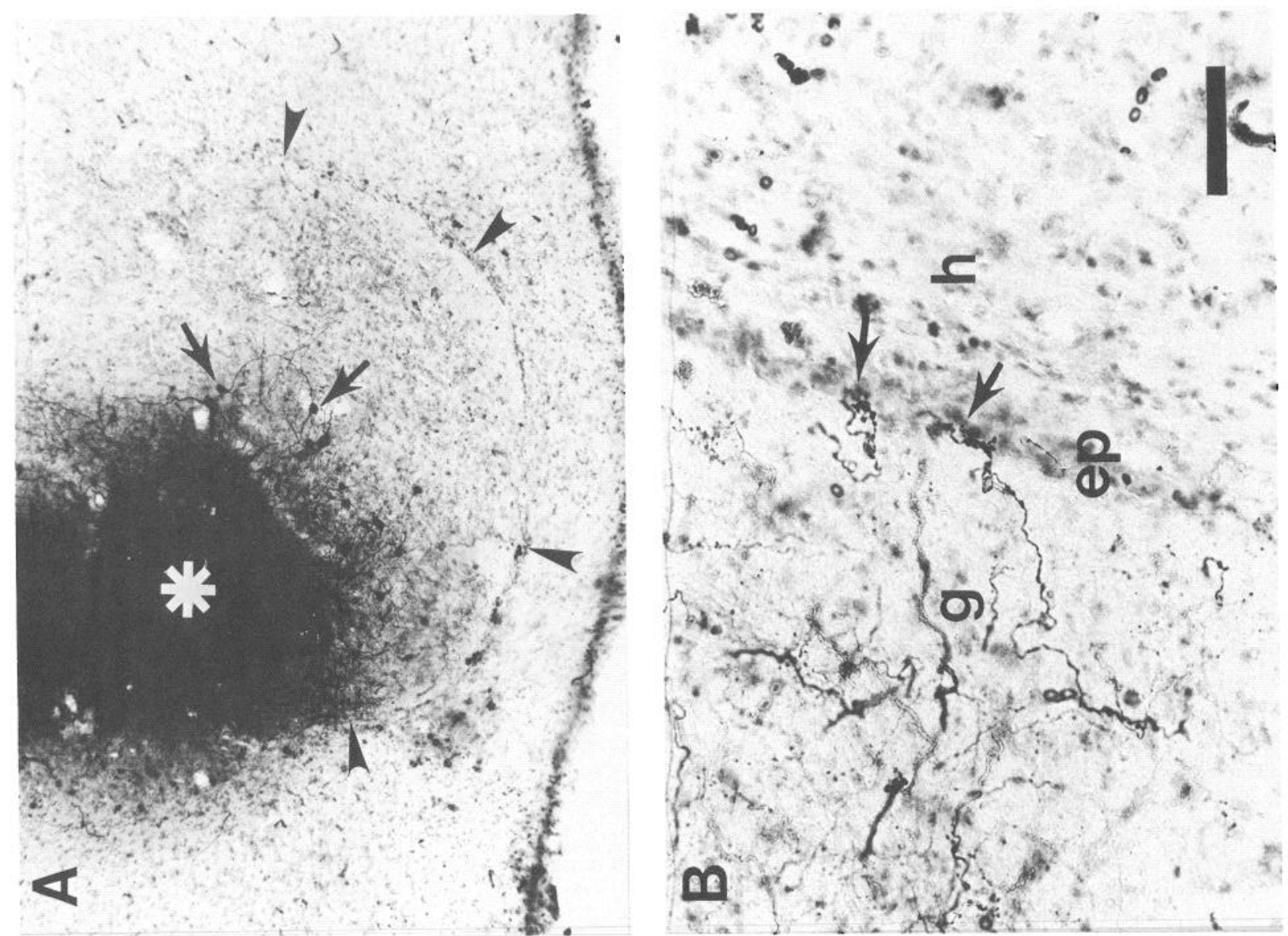

उ.

产远焉

ธี

.

जे

舟高

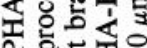
\%.

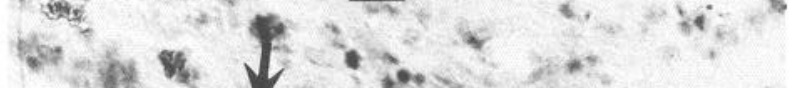

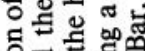

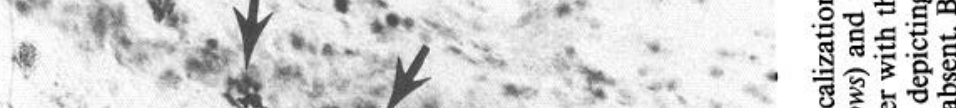

ite.

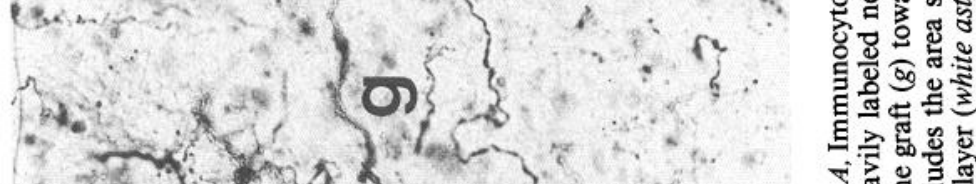

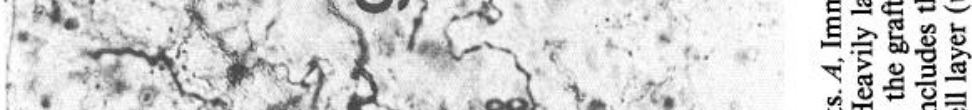

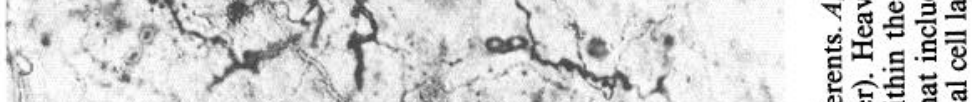

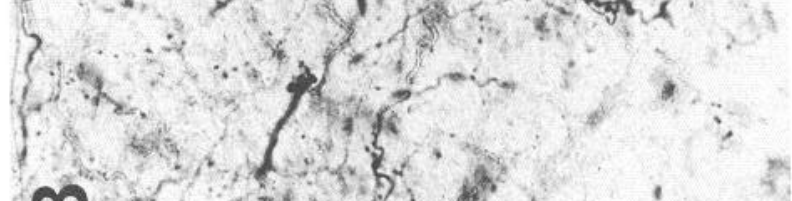

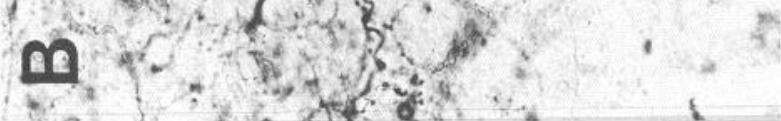

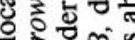

बु क्ष

ह

은

링

요

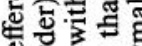

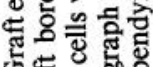

0 政

0 o 을

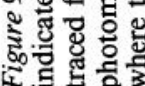



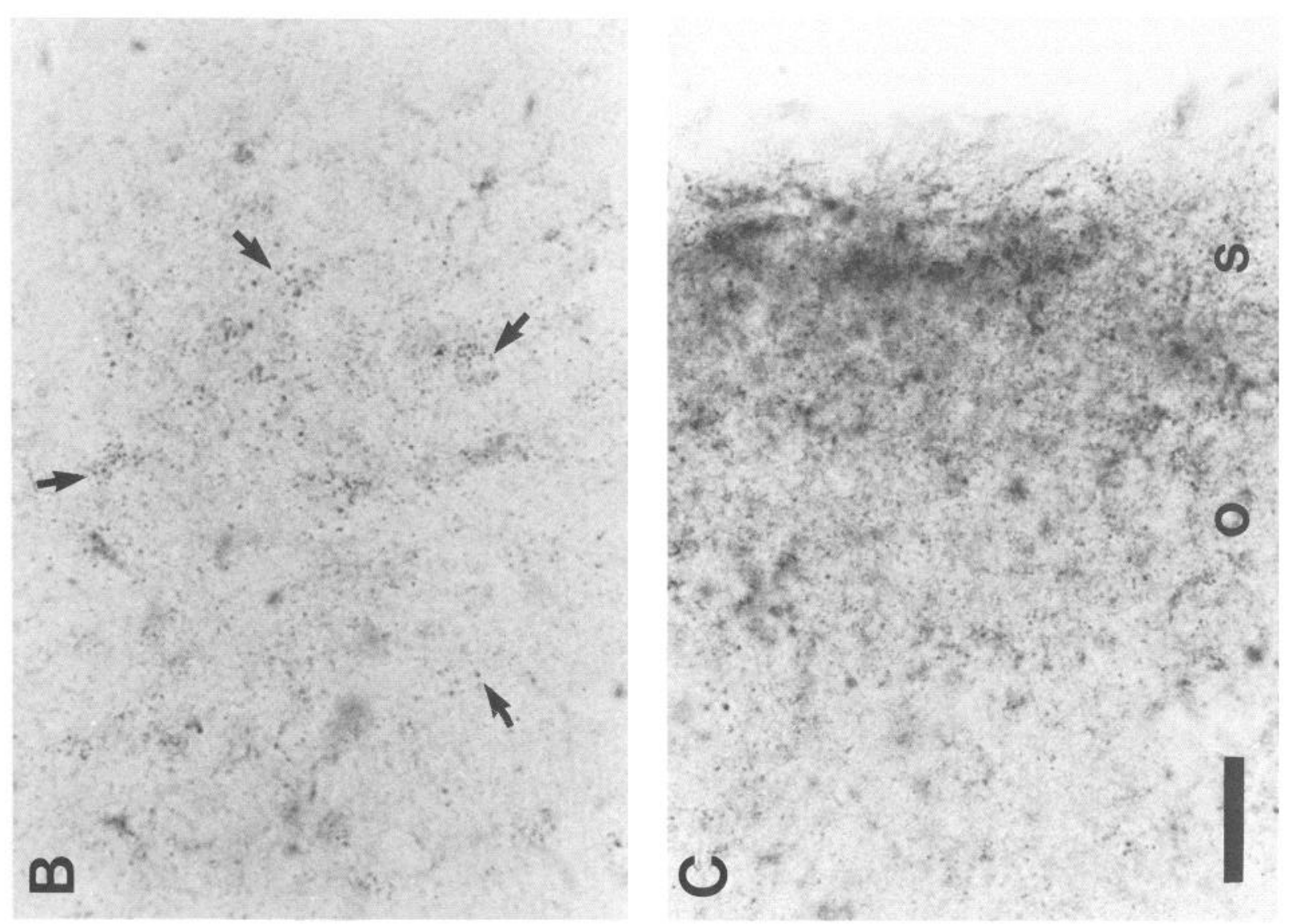

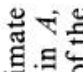

중형ㅇ

商实

运.

कीज

身

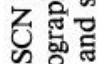

สี.

멸 흥

음을

늘

政

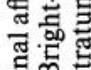

要里

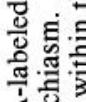

S.

흥

कัष

记

匀

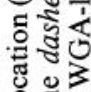

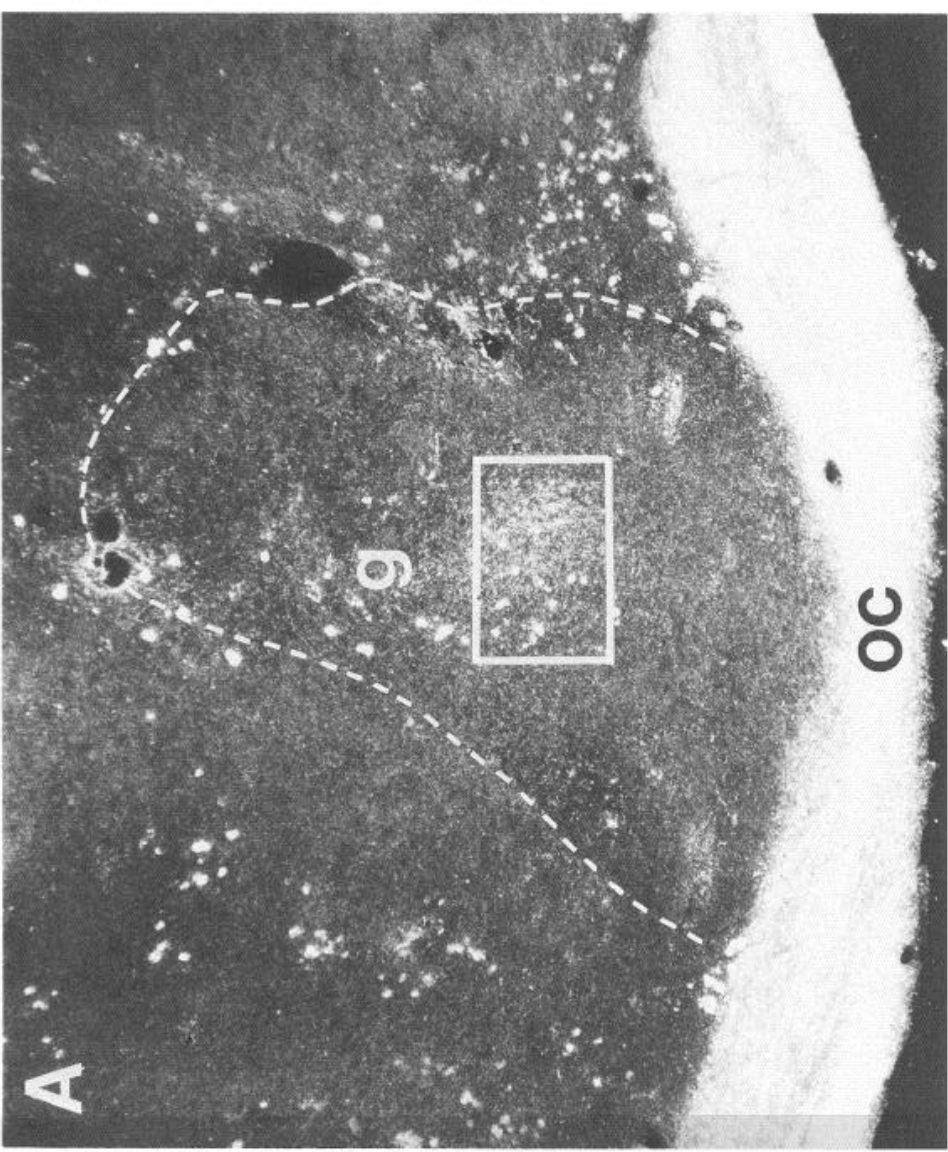

政

항.

跑

है

s.

氙它

政

है 멸

可

क के

명

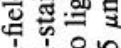

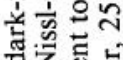

政

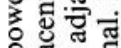

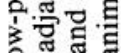

트명

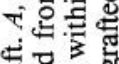

氙的

통ㅎㅇ

웜을

的势

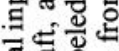

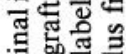

乐瓷

ㄷㅇㅇㅇㅛ

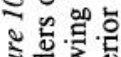

绿此 
clusters. Retinal innervation was not apparent in other grafts containing well-defined VIP cell clusters, possibly because of their placement at a greater distance from the optic chiasm. Intraocularly injected WGA heavily labeled terminals and cells in the superior colliculus (Fig. 10C) and the lateral geniculate in all animals.

\section{Discussion}

We have demonstrated that fetal SCN grafts can restore locomotor activity to SCN-lesioned hamsters in a majority of implanted animals. Following ablation of the SCN in neonatal animals, circadian rhythms of locomotor and drinking activity are not seen in adults, and retinal projections to the hypothalamus fail to form (Mosko and Moore, 1978). These observations suggest that neural mechanisms underlying circadian rhythmicity do not show functional or morphological plasticity after birth. Nevertheless, our results demonstrate that the developing $\mathrm{SCN}$, when transplanted to adult SCN-lesioned brains, is capable of both establishing at least some neural connections with the host brain and restoring circadian rhythms of locomotor activity. Furthermore, the failure of cerebellar transplants to reinstate locomotor rhythmicity indicates that this effect of SCN transplants is specific.

Visual inspection of the running records of grafted animals clearly indicates that SCN implants reestablish organized locomotor activity in SCN-lesioned animals. However, evidence from other studies suggests that ultradian patterns of locomotor activity may persist following complete SCN lesions (Rusak, 1977). Therefore, it is possible that $\mathrm{SCN}$ transplants that restore overt behavioral rhythms may do so by organizing oscillators that survive the SCN lesions into a normal circadian structure.

Grafts that restored locomotor rhythmicity contained peptidergic cells that possessed an organization remarkably similar to that of the intact SCN (Card and Moore, 1984). In the SCN of normal hamsters, VIP cells and NPY fibers are segregated in the ventrolateral portion, while parvocellular VP cells, SOM cells, and VIP fibers are located primarily in the dorsomedial division of this nucleus. VIP cells of the rat SCN have been shown to coexpress PHI (Moore et al., 1985), and evidence from serial sections suggests a similar colocalization in our grafts. With the notable absence of SOM cells, and some reorientation with respect to the host brain (see Fig. 5), the neuropeptide organization of the intact SCN was preserved within functional grafts. Evidence from one animal that remained arrhythmic despite the presence of VIP, but without NP- or VP-positive cells, suggests that the latter may be necessary for restoration of locomotor rhythmicity. Conversely, the absence of immunoreactive SOM cells in functional grafts of this study suggests that the expression of this neuropeptide component of the intact SCN may not be necessary for locomotor rhythmicity. Ilowever, because these animals were not pretreated with colchicine, an inhibitor of axonal transport, cells with low peptide content may not have been visible. Therefore, these differences may reflect the relative level of peptide expression within the graft and not the presence or absence of a particular neuropeptide phenotype.

Evidence from PHA-L applications into several grafts, and the immunostaining of VIP fibers exiting the grafts, suggests that some neurons in the transplant establish efferent connections with the host brain. When iontophoretically applied, PHA-L is transported in a predominantly anterograde direction (Gerfen and Sawchencko, 1984). Given the mode of delivery used here and the absence of labeled cells outside the graft, PHA-L fibers in the host brain were almost certainly efferents from the graft. Nevertheless, we did not determine in this study whether PHAL-labeled graft efferents were actually those VIP or VP fibers arising from the graft. Furthermore, the functional recovery shown by the hamster bearing an implant located in the lateral ventricle, in which the graft appeared to lack direct contact with the host brain (see Fig. 4B), suggests that a humoral signal may be adequate to sustain locomotor rhythms. Future experiments systematically varying the placement of whole tissue implants and rigorously testing for graft-host connections may help resolve this issue.

In 4 subjects, grafts situated in close physical proximity to the optic chiasm received direct projections from the retina. This finding is interesting in light of the previously reported lack of morphological plasticity in retinal input to the adult hypothalamus (Mosko and Moore, 1978) and suggests that such regrowth is possible, given an appropriate target. The punctate staining of WGA-labeled retinal afferents in this study is similar to that described previously in the rat visual system (Ruda and Coulter, 1982). Preliminary observations at an ultrastructural level indicate that WGA-labeled varicosities within the graft represent lysosomes and multivesicular bodies within both axon terminals and dendrites postsynaptic to them, an observation in agreement with the reported transneuronal transport of this lectin (Ruda and Coulter, 1982).

In addition to the observed direct retinal input, NPY fibers entering the transplant, some of which could represent LGN afferents, may provide an alternate route for photic input (Card and Moore, 1982; Harrington et al., 1985). However, neither of these inputs was sufficient to restore entrainment at the light intensities used in this experiment. Future experiments involving phase shifts and light-intensity thresholds will determine whether grafts can reestablish entrainment to a LD cycle.

We were surprised to observe a split pattern of locomotor activity in 9 out of 10 successful graft recipients during exposure to $\mathrm{DD}$, as intact hamsters do not show splitting in these conditions (Pittendrigh and Daan, 1976; Turek et al., 1982). All of the animals were implanted with tissue from 2 donors, and 8 of these grafts contained at least 2 separate clusters of VIP and NP/VP cells, with associated NPY fibers. The appearance of splitting in grafted animals may depend either on the way in which clusters of graft cells interact with one another, or on the way these clusters interact with the remaining circadian structure of the host. However, the issue of whether splitting is associated with the operation of 2 independent suprachiasmatic nuclei remains controversial, since animals with unilateral SCN lesions continue to split (see fig. 5 in Davis and Gorski, 1984; Pickard and Turek, 1983b).

Animals with SCN lesions maintain full testicular function despite exposure to nonstimulatory (short) photoperiods. The absence of testicular regression in DD in SCN-grafted animals showing free-running locomotor rhythms indicates that restoration of $\mathrm{SCN}$ function by fetal grafts was not complete. This finding is consistent with observations that reproductive responses to photoperiod can be dissociated from other circadianbased functions of the SCN (Pickard and Turek, 1983a; Bartness et al., 1985). Projections from the SCN to the hypothalamic paraventricular nucleus (PVN), some of which contain VIP, are believed to mediate reproductive responses to day length (Sims et al., 1980; Silverman et al., 1981; Lehman et al., 1984; Eskes and Rusak, 1985; Nunez et al., 1985). In this study, immuno- 
reactive VIP fibers could be traced across the border of the graft into the adjacent tuberal hypothalamus of the host, but could not be traced consistently or in great numbers dorsally toward the PVN. Perhaps a more extensive outgrowth from VIP cells or other neurons in the graft toward the PVN is necessary to restore gonadal response to day length.

While the finding that fetal grafts can restore locomotor rhythmicity in SCN-lesioned hamsters is consistent with the hypothesis that this area functions as a master oscillator, direct proof awaits a demonstration of a transference to the host of some characteristic of the donor's rhythm (Zimmerman and Menaker, 1979; Page, 1982). Further experiments using SCN grafts may reveal whether other behavioral and endocrine rhythms are restored, the function and synaptic connections of specific neuropeptide constituents of the $\mathrm{SCN}$, and the neural and/or endocrine pathways by which the SCN regulates circadian function.

Note added in proof: In a recent report, Decoursey and Buggy (1986) have also demonstrated that fetal SCN grafts can restore free-running rhythms to SCN-lesioned hamsters.

\section{References}

Arendash, G. W., and R. R. Gorski (1982) Enhancement of sexual behavior in female rats by neonatal transplantation of brain tissue from males. Science 217: 1276-1278.

Bartness, T. J., E. L. Bittman, and G. N. Wade (1985) Paraventricular nucleus lesions exaggcratc dictary obcsity but block photoperiod-induced weight gains and suspension of estrous cyclicity in Syrian hamsters. Brain Res. Bull. 14: 427-430.

Bjorklund, A., and U. Steveni (1984) Intracerebral neural implants: Neural replacement and reconstruction of damaged circuits. Annu. Rev. Neurosci. 1: 279-308.

Card, J. P., and R. Y. Moore (1982) Ventral lateral geniculate nucleus efferents to the rat suprachiasmatic nucleus exhibit avian pancreatic polypeptide like immunoreactivity. J. Comp. Neurol. 206: 390-396.

Card, J. P., and R. Y. Moore (1984) The suprachiasmatic nucleus of the golden hamster: Immunohistochemical analysis of cell and fiber distribution. Neuroscience 13:415-431.

Davis, F. C., and R. A. Gorski (1984) Unilateral lesions of the hamster suprachiasmatic nuclei: Evidence for redundant control of circadian rhythms. J. Comp. Physiol. (A) 154: 221-232.

DeCoursey, P. J., and J. Buggy (1986) Restoration of locomotor rythmicity in SCN-lesioned golden hamsters by transplantation of fetal SCN. Neurosci. Abstr. 12: 210.

Drucker-Colin, R., R. Aguliar-Roblero, F. Garcia-Herandez, F. Fernandez-Cancino, and F. B. Rattoni (1984) Fetal superchiasmatic nucleus transplants: Diurnal rhythm recovery of lesioned rats. Brain Res. 311: 353-357.

Elliott, J. A. (1976) Circadian rhythms and photoperiodic time measurement in mammals. Fed. Proc. 35: 2339-2346.

Elliott, J. A. (1981) Circadian rhythms, entrainment, and photoperiodism in the Syrian hamster. In Biological Clocks in Seasonal Reproductive Cycles, B. K. Follett and D. E. Follett, eds., pp. 203-217, Wiley, New York.

Eskes, G. A., and B. Rusak (1985) Horizontal knife cuts in the suprachiasmatic area prevent hamster gonadal responses to photoperiod. Neurosci. Lett. 61: 261-266.

Gash, D. M., and J. R. Sladek, Jr. (1984) Functional and non-functional transplants: Studies with grafted hypothalamic and preoptic neurons. Trends Neurosci. 7: 391-394.

Gaston, S., and M. Menaker (1967) Photoperiodic control of hamster testis. Science 158: 925-928.

Gerfen, C. R., and P. E. Sawchenko (1984) An anterograde neuroanatomical tracing method that shows the detailed morphology of neurons, their axons and terminals: Immunohistochemical localization of an axonally transported plant lectin, Phaseolus vulgaris leucoagglutinin (PHA-L). Brain Res. 290: 219-238.

Gibson, M. J., D. T. Krieger, H. M. Charlton, E. A. Zimmerman, A. J. Silverman, and M. J. Perlow (1984) Mating and pregnancy occur in genetically hypogonadal mice with preoptic area brain grafts. Science 225: 949-951.
I Iarrington, M. E., D. M. Nance, and B. Rusak (1985) NPY-like immunoreactivity in the geniculo-suprachiasmatic tract. Brain Res. Bull. 15: 465-472.

Inouye, S. E., and H. Kawamura (1979) Persistence of circadian rhythmicity in a mammalian hypothalamic "island" containing the suprachiasmatic nucleus. Proc. Natl. Acad. Sci. USA 76: 5962-5966.

Itoh, K., A. Konishi, S. Nomura, N. Mizuno, Y. Nakamura, and T. Sugimoto (1979) Application of coupled oxidation reaction to electron microscopic demonstration of horseradish peroxidase: Cobaltglucose oxidase method. Brain Res. 175: 341-344.

Kahn, R. M., W. Fifer, and R. Silver (1984) Automatic monitoring of temperature and/or location: $\Lambda$ computer-controlled radiotelemetry system. Behav. Res. Methods Intrum. Comp. 16: 533-537.

Krieger, D. T., M. J. Perlow, M. J. Gibson, T. F. Davies, E. A. Zimmerman, M. Ferin, and H. M. Charlton (1982) Brain grafts reverse hypogonadism of gonadotropin releasing hormone deficiency. Nature 298: 468-471.

Lehman, M. N., E. L. Bittman, and S. W. Newman (1984) Role of the hypothalamic paraventricular nucleus in neuroendocrine responses to daylength in the golden hamster. Brain Res. 308: 25-32.

Moore, R. Y., and V. B. Eichler (1972) Loss of a circadian adrenal corticosterone rhythm following suprachiasmatic lesions in the rat. Brain Res. 42: 201-206.

Moore, R. Y., J. Speh, and J. P. Card (1985) Vasoactive intestinal polypeptide (VIP) and peptide histidine isoleucine (PHI) co-localize in neurons of the rat suprachiasmatic nucleus (SCN). Neurosci. Abstr. 11: 1139 .

Mosko, S. S., and R. Y. Moore (1978) Neonatal suprachiasmatic nucleus ablation. Absence of functional and morphological plasticity. Proc. Natl. Acad. Sci. USA 75: 6243-6246.

Nunez, A. A., M. H. Brown, and T. G. Youngstrom (1985) Hypothalamic circuits involved in the regulation of seasonal and circadian rhythms in male golden hamsters. Brain Res. Bull. 15: 149-153.

Page, T. L. (1982) Transplantation of the cockroach circadian pacemaker. Science 216:73-75.

Pickard, G. E., and F. W. Turek (1983a) The hypothalamic paraventricular nucleus mediates the photoperiodic control of reproduction but not the effects of light on the circadian rhythm of activity. Neurosci. Lett. 43: 67-72.

Pickard, G. E., and F. W. Turek (1983b) The suprachiasmatic nuclei: Two circadian clocks? Brain Res. 268: 201-210.

Pittendrigh, C. S., and S. Daan (1976) A functional analysis of circadian pacemakers in nocturnal rodents. V. Pacemaker structure: A clock for all seasons. J. Comp. Physiol. 106: 333-355.

Reppert, S. M., and W. J. Schwartz (1983) Maternal coordination of the fetal biological clock in utero. Science 220:969-971.

Ruda, M., and J. D. Coulter (1982) Axonal and transneuronal transport of wheat germ aggulutinin demonstrated by immunocytochemistry. Brain Res. 249: 237-246.

Rusak, B. (1977) The role of the suprachiasmatic nuclei in the generation of circadian rhythms in the golden hamster, Mesocricetus auratus. J. Comp. Physiol. 118: 145-164.

Rusak, B., and L. P. Morin (1976) Testicular responses to photoperiod are blocked by lesions of the suprachiasmatic nuclei in golden hamsters. Biol. Reprod. 15: 366-374.

Rusak, B., and I. Zucker (1979) Neural regulation of circadian rhythms. Physiol. Rev. 59: 449-526.

Sawaki, Y., I. Nihonmatsu, and H. Kawamura (1984) Transplantation of the neonatal suprachiasmatic nuclei into rats with complete bilateral suprachiasmatic lesions. Neurosci. Res. 1: 67-72.

Schwartz, W. J., and H. Gainer (1977) Suprachiasmatic nucleus: Use of ${ }^{14} \mathrm{C}$-labeled deoxyglucose uptake as a functional marker. Science 197: 1089-1091.

Silverman, A. J., D. L. Hoffman, and E. A. Zimmerman (1981) The descending afferent connections of the paraventricular nucleus of the hypothalamus (PVN). Brain Res. Bull. 6: 47-61.

Sims, K. B., D. L. Hoffman, S. I. Said, and E. A. Zimmerman (1980) Vasoactive intestinal polypeptide (VIP) in mouse and rat brain: An immunocytochemical study. Brain Res. 186: 165-183.

Stephan, F. K., and I. Zucker (1972) Circadian rhythms in behavior and locomotor activity of rats are eliminated by hypothalamic lesions. Proc. Natl. Acad. Sci. USA 69: 1583-1586.

Stetson, M. H., and M. Watson-Whitmyre (1976) Nucleus suprachiasmaticus: The biological clock of the hamster? Science 292: 197-199. 
'I urek, F. W., and S. H. Losee (1979) Photoperiodic inhibition of the reproductive system: A prerequisite for the induction of the refractory period in hamsters. Biol. Reprod. 20: 611-616.

Turek, F. W., D. J. Earnest, and J. Swann (1982) Splitting of the circadian rhythm of activity in hamsters. In Vertebrate Circadian
Systems, J. Aschoff, ed., pp. 203-214. Springer-Verlag, Berlin, Heidelberg.

Zimmerman, N. H., and M. Menaker (1979) Neural connections of the sparrow pineal: Role in circadian control of activity. Science 190: 477-479. 